\title{
Hepatitis C: looking at a virus that hasn't been
}

seen

\author{
L R Overby
}

were used extensively but failed to detect hepatitis $\mathrm{C}$ virus (HCV). During this period the disease was characterised as a long term, persisting infection, that was initially mild and asymptomatic. Serious chronic liver diseases developed progressively over a period of years. The breakthrough came through molecular cloning of the nucleic acids extracted from chimpanzee plasma containing a high degree of NANB hepatitis infectivity. ${ }^{2}$ The sequence of the first identified clone encoded a 55 amino acid peptide containing an immunodominant epitope that reacted only with antiserum from NANB hepatitis patients. ${ }^{3}$ The sequence of a positive strand RNA of about 10000 ribonucleotides was determined eventually by overlapping clones, and was designated the $\mathrm{HCV}$ genome. ${ }^{4}$ Our current knowledge of $\mathrm{HCV}$ is extensive, derived exclusively from studying the clinical nature of the disease and from the information encoded within the genomic sequence.

\section{Genomic organisation}

The organisation of the HCV genomic RNA is illustrated in Figure 1. The original isolate (HCV-1) was a positive-sense RNA of 9401 ribonucleotides, containing a poly-A tail at the $3^{\prime}$ end. The sequence contained a 5 ' untranslated region of 341 bases, followed by a long open reading frame encoding for a polyprotein of 3011 amino acids, and a 3'-untranslated region of about 27 bases. This RNA structure is similar to that of the well known flaviviruses that infect both animals and humans. The calculated hydrophobic/hydrophilic properties of the HCV encoded polyprotein are similar to typical flaviviruses and pestiviruses. Based on analogy with these viruses the probable cleavage points of the HCV polyproteins are indicated in Figure 1. The indicated size and function of the viral proteins are supported by in vitro translation of HCV-RNA and characterisation of the translation products. ${ }^{5}$ Consistent with the known functions of most flavivirus proteins, the three $\mathrm{N}$-terminal $\mathrm{HCV}$ proteins are probably structural (C, E1, E2/NS1), and the four C-terminal proteins (NS2, NS3, NS4, NS5) function for viral replication. Growth of $\mathrm{HCV}$ in culture will be necessary for the final confirmation of the function of the proteins.

\section{Genomic heterogeneity}

After the first HCV genomic sequence was identifed, ${ }^{23}$ a number of other $\mathrm{HCV}$ isolates from different parts of the world were obtained
Correspondence to: Dr L R Overby 28 Cherry Hills Court, Alamo, California 94507 , for almost 15 years. The techniques that successful in discovering $\mathrm{HAV}$ and $\mathrm{HBV}$ (serology and immune electronmicroscopy) 

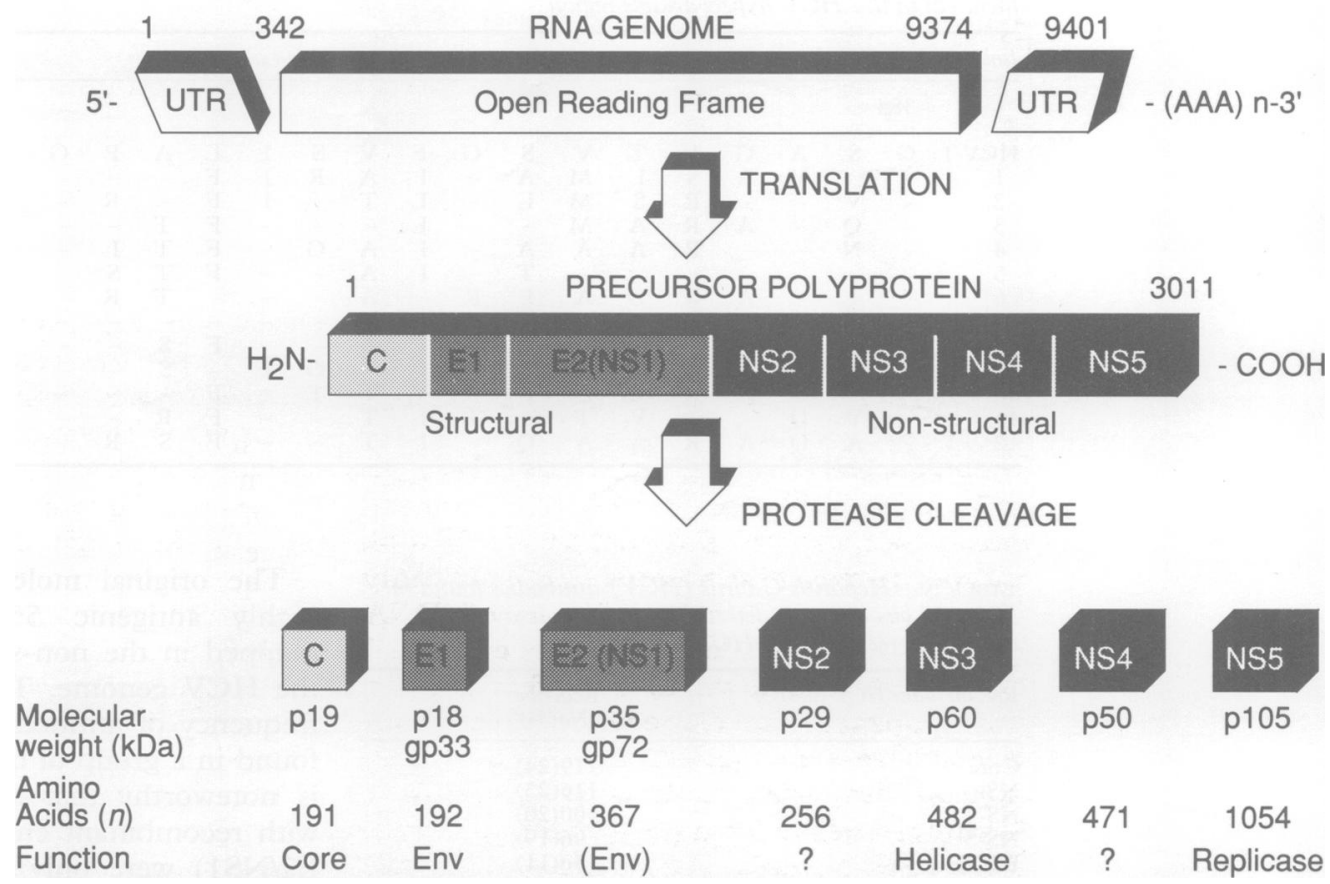

Figure 1 Predicted genomic organisation and processing of viral proteins of hepatitis $C$ virus-1 (HCV-1), based on analogy with typical flaviviruses and pestiviruses with similar genomes. UTR=untranslated region.

and sequenced. ${ }^{6-10}$ Comparisons of the nucleotide and the deduced polyprotein amino acid sequences of the isolates showed considerable heterogeneity in the genotypes. Okamoto et al have classified all reported full and partial sequences into four genotype classes, according to the degree of sequence homogeneity. ${ }^{10}$ This comparison is summarised in Table $I$. As illustrated, twelve additional isolates had $94 \%$ nucleic acid homology with the original HCV-1 sequence (type I). Eleven other isolates were only $78 \%$ homologous with $\mathrm{HCV}-1$ (type II). Type III and IV sequences were only $69 \%$ homologous with $\mathrm{HCV}-1$.

The genomic heterogeneity of HCV isolates is reflected in the amino acid sequences of the encoded precursor polyprotein. Table II shows the HCV-1 polyprotein amino acid homologies with each of the four genotype classes. As shown, the 5'-untranslated region and the $\mathrm{N}$-terminal $\mathrm{C}$ (core) protein regions are highly conserved in all genotypes. In contrast, the envelope regions ( $\mathrm{E} 1$ and $\mathrm{E} 2 \mathrm{NS} 1$ ), the nonstructural 2 (NS2) region, and the 3'-untranslated region are highly variable and poorly conserved.

A hypervariable region has been identifed at the $\mathrm{N}$-terminal region of the E2/NS1 cleavage protein (Fig 1). Every reported genomic sequence has a different amino acid sequence within the region of amino acid 384-408 of the polyprotein. Table III illustrates the variability of this region for 12 different viraemic patients in various geographical locations. In addition to hypervariability from infection to infection, mutations within this region occur at a high rate in individuals during the course of $\mathrm{HCV}$ infection.
TABLE I Classification of reported full and partial nucleic acid sequences of the hepatitis $C$ virus (HCV) genome according to percentage of homogeneity. $H C V-1, H C V-7$,

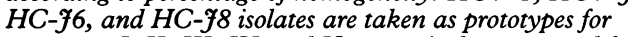
genotypes I, II, III, IV, and V, respectively, compared for homology with 40 other sequences ${ }^{10}$

\begin{tabular}{lllll}
\hline \multirow{2}{*}{$\begin{array}{l}\text { Type } \\
\text { (no of isolates) }\end{array}$} & \multicolumn{4}{l}{ Percentage homology of prototype isolate } \\
\cline { 2 - 5 } & I & II & $I I I$ & $I V$ \\
& $H C V-1$ & $H C V-\mathcal{F}$ & HC-76 & HC-f8 \\
\hline I(12) & 94 & 78 & 68 & 66 \\
II(11) & 78 & 91 & 67 & 65 \\
III(3) & 69 & 68 & 93 & 79 \\
IV(4) & 69 & 69 & 80 & 94 \\
\hline
\end{tabular}

TABLE II Comparison of hepatitis $C$ virus (HCV)-1 polyprotein amino acid sequences by region with the sequence in other isolates

\begin{tabular}{lcccc}
\hline Protein region & \multicolumn{4}{c}{ Genotype/\%homology with HCV-1 } \\
\cline { 2 - 5 } & $I$ & $I I$ & $I I I$ & $I V$ \\
\hline 5'-UTR & $(100)$ & $(98)$ & $(94)$ & $(94)$ \\
C & 99 & 98 & 90 & 90 \\
E1 & 94 & 79 & 60 & 55 \\
E2/NS1 & 93 & 78 & 71 & 74 \\
NS2 & 94 & 77 & 58 & 56 \\
NS3 & 97 & 91 & 81 & 81 \\
NS4 & 96 & 87 & 73 & 72 \\
NS5 & 97 & 84 & 70 & 69 \\
3'-UTR & $(96)$ & $(67)$ & $(30)$ & $(26)$ \\
\hline
\end{tabular}

^Nucleic acid homologies.

In general, highly conserved viral genomic regions may reflect a necessary function in the life cycle of viruses. Regions that are less conserved may be either unimportant for viral replication or may represent important viral strategies for escape from host defence mechanisms. The role of genomic variability in $\mathrm{HCV}$ infection and disease is not understood. Many functions have been suggested, for 
TABLE III Amino acid sequence variations in the hypervariable region of the hepatitis $C$ virus (HCV) precursor polyprotein. Amino acid number 348 represents the estimated N-terminus of the E2/NS1 viral protein. The sequences of 12 different isolates from various geographical areas are compared with the prototype HCV-1 sequence. No sequences are identical in this HCV hypervariable region

\begin{tabular}{ll}
\hline Isolate & Amino acid sequence \\
\hline 384 & 406
\end{tabular}

\begin{tabular}{|c|c|c|c|c|c|c|c|c|c|c|c|c|c|c|c|c|c|c|c|c|c|c|c|}
\hline HCV-1 & G & $\mathrm{S}$ & A & G & $\mathrm{H}$ & $\mathrm{T}$ & V & $S$ & G & F & V & $S$ & L & $\mathrm{L}$ & A & $P$ & G & A & $\mathrm{K}$ & $\mathrm{Q}$ & $\mathrm{N}$ & V & Q \\
\hline 1 & - & - & V & A & $S$ & I & M & A & - & I & A & $\mathrm{R}$ & $\bar{F}$ & $\bar{F}$ & - & - & - & - & $\mathrm{R}$ & - & D & I & - \\
\hline 2 & - & $\mathrm{V}$ & - & - & $\mathbf{R}$ & $S$ & $M$ & $\mathrm{~L}$ & - & $\mathrm{L}$ & $\mathrm{T}$ & - & I & $\mathrm{F}$ & - & $\mathbf{R}$ & - & - & - & - & $\mathrm{D}$ & - & - \\
\hline 3 & - & Q & - & A & R & A & $M$ & - & - & $\mathrm{L}$ & - & - & - & $\mathrm{F}$ & $\mathrm{T}$ & - & - & - & - & - & - & I & - \\
\hline 4 & - & $\hat{N}$ & - & - & R & A & A & A & - & I & A & G & - & $\mathrm{F}$ & $\mathrm{T}$ & $\mathrm{L}$ & - & - & - & - & - & - & - \\
\hline 5 & - & - & - & - & - & - & - & $\mathrm{T}$ & - & I & A & - & - & $\mathrm{F}$ & $\mathrm{T}$ & $S$ & - & - & - & - & - & I & - \\
\hline 6 & - & - & - & A & $\mathbf{R}$ & D & A & $\mathrm{F}$ & $\mathrm{R}$ & - & A & - & - & - & $\mathrm{T}$ & R & - & $P$ & $S$ & - & - & I & - \\
\hline 7 & - & A & - & A & $\mathrm{R}$ & $\mathrm{N}$ & A & $\mathrm{R}$ & $\mathrm{S}$ & $\mathrm{L}$ & $\mathrm{T}$ & - & - & - & - & - & - & - & $S$ & - & $\mathrm{K}$ & I & - \\
\hline 8 & - & A & - & $S$ & - & - & $\mathrm{T}$ & - & $\mathrm{T}$ & $\mathrm{L}$ & A & - & - & $\mathrm{F}$ & $S$ & - & - & - & S & - & $\mathrm{K}$ & I & - \\
\hline 9 & - & $\mathrm{T}$ & V & A & $\mathbf{R}$ & $S$ & $\mathrm{~T}$ & Q & - & $\mathrm{L}$ & - & G & $\mathrm{F}$ & - & $S$ & - & - & P & $S$ & - & - & I & - \\
\hline 10 & - & $\mathrm{T}$ & S & A & $\mathbf{R}$ & $\mathrm{N}$ & $\mathrm{T}$ & $\mathrm{F}$ & - & V & $\mathrm{T}$ & $\mathrm{T}$ & - & $\mathrm{F}$ & - & - & - & P & S & - & $\mathrm{K}$ & I & - \\
\hline 11 & - & V & Q & - & - & V & $\mathrm{T}$ & - & $\mathrm{T}$ & $\mathrm{L}$ & $\mathrm{T}$ & - & - & $\mathrm{F}$ & $\mathrm{R}$ & - & - & - & $S$ & - & $\mathrm{K}$ & I & - \\
\hline 12 & - & A & $\bar{Q}$ & A & R & A & A & Q & - & I & $\mathrm{T}$ & - & - & $\mathrm{F}$ & $S$ & $\mathrm{R}$ & - & $S$ & $S$ & - & $\mathrm{K}$ & I & - \\
\hline
\end{tabular}

TABLE IV Hepatitis $C$ virus (HCV) antibodies found in 500 paid blood donors detected by immunoassays using individual recombinant HCV proteins

\begin{tabular}{lr}
\hline Recombinant HCV antigen & $\begin{array}{r}\text { Reactive } \\
\text { No(\%) }\end{array}$ \\
\hline Core & $119(24)$ \\
NS-3 & $116(23)$ \\
NS-4 & $100(20)$ \\
NS-5 & $96(19)$ \\
E2NS-1 & $56(11)$ \\
E1 & $50(10)$ \\
\hline
\end{tabular}

example, different serotypes, escape mutants, pathogenic/non-pathogenic strains, duration of infection, cross neutralisation, multiple reinfections, cell tropism. Further studies with patients to correlate HCV sequence heterogeneity with disease severity, epidemiology, treatment, or prophylaxis may elucidate this.

\section{Immunobiology}

Recombinant $\mathrm{HCV}$ proteins (produced in bacteria, yeast, or mammalian cells) and synthetic peptide epitopes have been used in immunoassays to evaluate the immunogenicity of each of the viral proteins. Seroconversions to each viral protein have been observed throughout the course of infection but without a unique and consistent serological pattern.

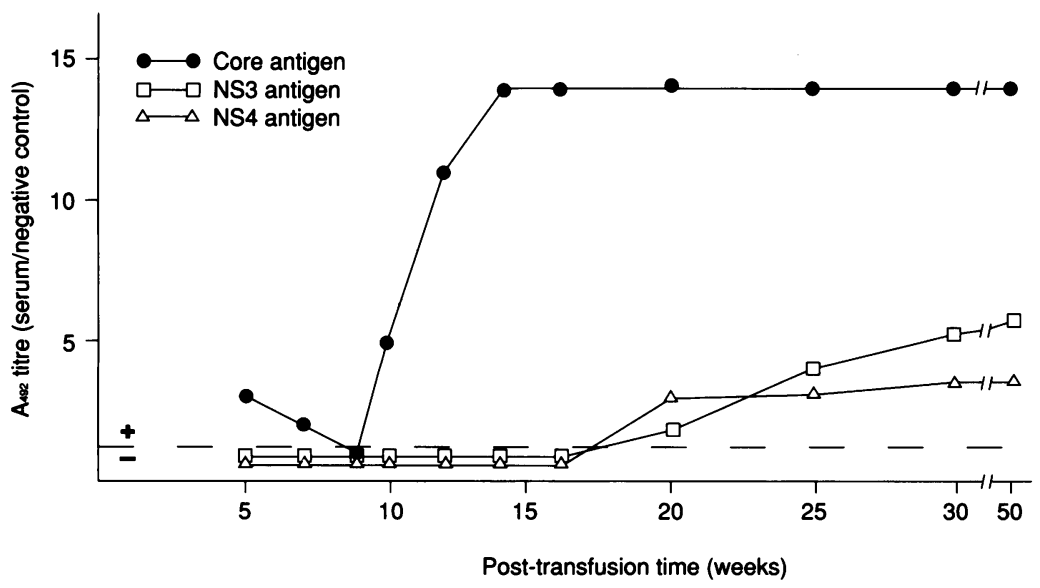

Figure 2 Time course of anti-hepatitis $C$ virus response to individual viral antigens in a patient with non- $A$, non- $B$ hepatitis associated with transfusion showing early seroconversion to the core antigen. Serum specimens were tested with enzyme immunoassays prepared with individual recombinant antigens.
The original molecular clone encoding a highly antigenic 55 amino acid peptide mapped in the non-structural NS4 region of the HCV genome. Table IV summarises the frequency of antibodies to six $\mathrm{HCV}$ proteins found in a group of high risk blood donors. It is noteworthy that seroconversions detected with recombinant envelope proteins (E1 and E2/NS1) were only $10 \%$ in this population compared with more than $20 \%$ for the nonstructural proteins. The $\mathrm{C}$ protein was found to be the most immunogenic in this population. In this group of seropositive donors, the various antibodies were distributed as follows: core $(94 \%), \mathrm{E} 1$ (44\%), E2/NS1 $(38 \%)$, NS4 $(75 \%)$, and NS5 $(69 \%)$. Thus, no one antibody would identify all infections. Further analyses indicated that all $\mathrm{HCV}$ infections in these donors could be identified with a combination of $\mathrm{C}, \mathrm{NS} 3$, and NS4 recombinant antigens. Commercial tests have been configured with these three antigens and are used widely to identify and interdict seropositive blood from transfusion services. HCV screening has made significant contributions to the safety of blood. The screening test has also been useful in epidemiological studies, identifying the agent in a large percentage of sporadic NANB cases of hepatitis.

Thus far, no serological pattern of $\mathrm{HCV}$ antibodies has been associated with disease diagnosis or prognosis, duration of infection, or virus life cycle. The presence of $\mathrm{HCV}$ antibodies, determined by immunoassays, indicates only present or past infection. In a number of retrospective studies of serial blood samples taken during $\mathrm{HCV}$ infection, anti$\mathrm{HCV}$ core occurred early and persisted at a high titre (Fig 2). Antibodies to non-structural proteins occurred later at a relatively lower titre. In other patients with a similar clinical history, however, the studies showed early seroconversion to non-structural proteins, without seroconversion to the core protein for more than one year (Fig 3). A serological profile for staging the course of disease and for monitoring therapy is needed urgently.

\section{Challenges and opportunities}

We have 'seen' the HCV in terms of the information encoded in its genomic sequence. 


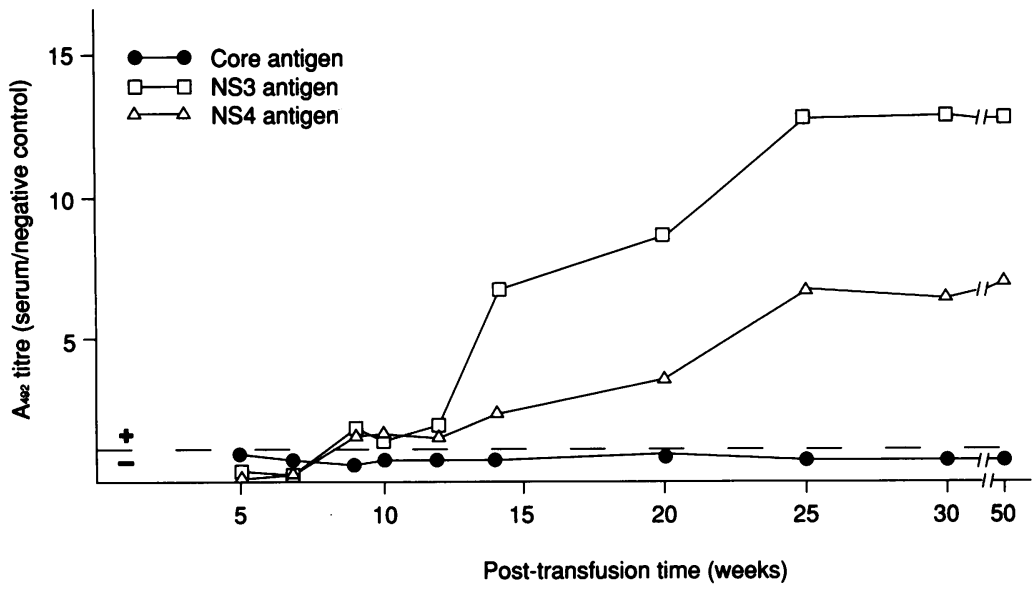

Figure 3 Time course of anti-hepatitis $C$ virus response to individual viral antigens in a patient with non- $A$, non- $B$ hepatitis associated with transfusion showing early seroconversion to non-structural antigens and absence of seroconversion to core antigen.
The viral proteins have been produced in recombinant organisms and partially characterised, both biophysically and serologically. The infection can be identified and asymptomatic carriers prevented from making blood donations. Initially, most $\mathrm{HCV}$ infections are mild or asymptomatic but they can lead to serious chronic liver diseases over a period of many years. Prevention of new infections and successful treatment for those already infected may, in time, lead to control of this worldwide health problem.

Although molecular studies can teach us much about the virus, our complete understanding can be accelerated through the growth of $\mathrm{HCV}$ in cell culture and visualisation by electronmicroscopy. A combination of molecular, clinical, and virological studies will be needed to answer many pressing questions about $\mathrm{HCV}$ infection, namely:

Is there ever recovery from infection followed by persisting immunity?

Is there an immunological basis for passive or active immunity?
What is the molecular basis for association with hepatocellular carcinoma after long term $\mathrm{HCV}$ infection?

What is the basis for the long persistence of $\mathrm{HCV}$ infection?

What is the major risk factor for sporadic $\mathrm{HCV}$ infection?

Are there transmission vectors for $\mathrm{HCV}$ infection?

Is there another blood borne hepatotropic virus?

Progress has been considerable since the $\mathrm{HCV}$ genome was identified by molecular cloning, but there are still more questions than answers. Hopefully, in this era of molecular genetics, many of these answers will be apparent before we know what HCV actually 'looks' like.

1 Alter HJ, Holland PV, Purcell RH. The emerging pattern of post-transfusion hepatitis. Am f Med Sci 1975; 27: 329-34.

2 Choo QL, Kuo G, Weiner AJ, Overby LR, Bradley DW, Houghton $M$. Isolation of a CDNA clone derived from a blood-borne non-A, non-B viral hepatitis genome. Science 1989; 224: 359-62.

3 Kuo G, Choo QL, Alter HJ, et al. An assay for circulating antibodies to a major etiologic virus of human non-A, non-B hepatitis. Science 1989; 244: 362-4.

4 Choo QL, Richman KH, Han JH, et al. Genetic organization and diversity of the hepatitis $\mathrm{C}$ virus. Proc Natl Acad Sci USA 1991; 88: 2451-5.

5 Matsuura Y, Harada S, Suzuki R, et al. Expression of processed envelope protein of hepatitis $\mathrm{C}$ virus in mammalian and insect cells. 7 Virol 1992; 66: 1425-31.

6 Incauspe G, Zebedee $S$, Lee DH, Sugitani $M$, Nasoff $M$, Prince AM. Genomic structure of the human prototype strain of hepatitis C: comparison with American and Japanese isolates. Proc Natl Acad Sci USA 1991; 88: $10,292-6$

7 Kato N, Hijikata M, Ootsuyama Y, et al. Molecular cloning of the human hepatitis $C$ genome from Japanese patients with non-A, non-B hepatitis. Proc Natl Acad Sci USA 1990; 87: 9524-8.

8 Takamizawa A, Mori C, Fuke I, et al. Structure and organization of the hepatitis $\mathrm{C}$ virus genome isolated from human carriers. $\mathcal{F}$ Virol 1991; 65: 1105-13.

9 Okamoto H, Okada S, Sugiyama Y, et al. Nucleotide sequence of the genomic RNA of hepatitis virus isolated from a human carrier: comparison with reported isolates for conversed and divergent regions. $\mathcal{F}$ Virol 1991; 72: $2697-704$

10 Okamoto H, Kurai K, Okada S, et al. Full-length sequence of a hepatitis $\mathrm{C}$ virus genome having poor homology to reported isolates: comparative study of four distinct reported isolates: comparative study
genotypes. Virology 1991; 188: 331-41. 